\title{
Pengaruh Implementasi Praktik Community Based Medical Education (CBME) terhadap Peningkatan Kemampuan Soft Skills Kepemimpinan dan Komunikasi pada Mahasiswa DIII Kebidanan
}

Evi Sri Suryani', Yuni Susanti Pratiwi ${ }^{2}$, Endang Sutedja ${ }^{3}$, Farid Husin ${ }^{4}$, Dasim Budimansyah ${ }^{5}$, Jusuf F. Efendi ${ }^{6}$, Firman F Wirakusumah ${ }^{7}$

${ }^{1}$ Mahasiswa Magister Kebidanan Fakultas Kedokteran Universitas Padjadjaran

${ }^{2}$ Departemen Fisiologi Fakultas Kedokteran Universitas Padjadjaran

${ }^{3}$ Departemen Kulit dan Kelamin Fakultas Kedokteran Universitas Padjadjaran

${ }^{4}$ Departemen Epidemiologi dan Biostatistika Fakultas Kedokteran Universitas Padjadjaran

${ }^{5}$ Universitas Pendidikan Indonesia

${ }^{6}$ Departemen Obstetri dan Ginekologi Fakultas Kedokteran Universitas Padjadjaran

\begin{abstract}
Abstrak
Pendidikan kesehatan berbasis masyarakat/ Community Based Medical Education (CBME) diperlukan untuk meningkatkan kompetensi mahasiswa kebidanan. Mahasiswa kebidanan harus mempunyai kemampuan hard skills dan soft skills yang unggul untuk bisa menjadi bidan profesional yang kompeten mampu memberikan intervensi berbasis bukti, mampu berkomunikasi, mampu memimpin dan bekerjasama dalam tim, serta mampu memberikan solusi pada permasalahan yang sulit dalam pelayanan kebidanan. Implementasi program tersebut selama ini belum pernah dianalisis lebih lanjut terutama tercapainya tujuan pembelajaran soft skills meliputi kepemimpinan dan komunikasi.Penelitian ini bertujuan untuk menganalisis pengaruh implementasi praktik CBME terhadap peningkatan kemampuan kepemimpinan dan komunikasi mahasiswa kebidanan. Penelitian ini merupakan penelitian kuantitatif dengan pre eksperimen one group pre-post test design.Subjek dalam penelitian ini adalah mahasiswa kebidanan semester VI di Akademi Kebidanan YLPP Purwokerto. Instrumen penelitian menggunakan kuesioner.Terdapat pengaruh implementasi praktik Community Based Medical Education terhadap peningkatan kemampuan soft skills kepemimpinan dan komunikasi mahasiswa kebidanan yang dilihat dari nilai $p$-value $(0.000)$ kurang dari nilai $\alpha(0.05)$. Simpulan CBME merupakan salah satu metode pembelajaran yang efektif untuk meningkatkan kemampuan kepemimpinan dan komunikasi mahasiswa kebidanan
\end{abstract}

Kata kunci: Community Based Medical Education, kepemimpinan, komunikasi 


\title{
Effect of Implementation Practices of Community Based Medical Education (CBME) to Improving Soft Skills of Leadership and Communication at Midwifery Diploma Students
}

\begin{abstract}
Midwifery education is education program that is held as one of effort to produce professional midwifery expert in creating and increasing the quality of midwifery service. Community based medical education (CBME) is needed to increase midwifery students competency. To be a professional midwife, Midwifery students have to have good hardskills and softskills so they are able to give intervention based evidence, make good communication, make good cooperation in team and give solution for difficult problem in midwifery service. During this time, Such program implementation is not analized yet further especially in achieving softskill learning goal consist of leadership and communication. The aim of this research is to analyze the influence implementation practice of community based medical education towards increasing midwifery student's ability of leadership and communication. This research used quantitative with pre-experiment with one group pre and post test design. The subject of this research was VI semester students of YLPP midwifery academy of Purwokerto, midwife as field. Sample was total sampling. The instrument of research used questionnaire. There was influence implementation practice of community based medical education towards increasing midwifery student's ability of leadership and communication softskills that was seen from p-value (0.000) less than a (0.05) value.Conclusion of this study CBME is o effective learning methods to improve leadership and communication midwifery students
\end{abstract}

Keywords: Community based medical education, leadership, communication

\section{Pendahuluan}

Bidan sebagai penyedia layanan kesehatan selama periode reproduksi memiliki kesempatan untuk mendorong perempuan membuat pilihan yang berdampak positif pada kesehatan ibu dan janin. Diperlukan pendidikan kebidanan yang relevan untuk kebutuhan masa kini dan mendatang terhadap pelayanan kebidanan.The State of World's Midwifery telah mengidentifikasi bahwa sebagian besar negara berkembang tidak memiliki bidan profesional yang mampu mengelola tingginya jumlah kehamilan yang $15 \%$ diantaranya mengakibatkan komplikasi obstetrik. Profil lulusan bidan profesional tidak hanya unggul pada prestasi akademik (hard skills) namun unggul pula pada kemampuan kepribadian (soft skills). ${ }^{1,2}$

Mahasiswa kebidanan selain mempunyai dan menguasai keterampilan teknis kebidanan, juga harus mempunyai ilmu berkomunikasi dan jiwa kepemimpinan yang tinggi. Pentingnya penguasaan soft skills ketika bidan memasuki dunia kerja menuntut lembaga pendidikan kebidanan merancang program pengembangan soft skills dalam pembelajaran sebagai sarana membangun etika kerja dengan mahasiswa diikutkan dalam pembelajaran langsung dengan masyarakat. ${ }^{3,4}$

Pendidikan kesehatan berbasis masyarakat/ Community Based Medical Education (CBME) mencetak bidan sebagai tenaga kesehatan yang terampil untuk mengurangi angka kematian ibu dan bayi baru lahir telah diperkenalkan dibeberapa negara berkembang seperti Sri Lanka, India, Indonesia dan negara-negara Afrika. $^{5}$ Pendidikan kesehatan berbasis masyarakat/ CBME di dalam pendidikan kebidanan dinamakan praktik Pembangunan Kesehatan Masyarakat Desa (PKMD). Kegiatan ini bertujuan agar mahasiswa mampu menerapkan kebidanan komunitas dimasyarakat serta memberikan kesempatan kepada mahasiswa untuk berinteraksi dengan masyarakat dari berbagai budaya, dan latar belakang etnis dan sosial yang berbeda. ${ }^{1}$

Kegiatan dalam pembelajaran CBME antara lain mahasiswa melaksanakan kunjungan rumah sehingga mahasiswa berhadapan dengan keluhan ibu hamil, ibu bersalin dan nifas secara langsung sehingga mahasiswa dituntut untuk bisa 
memberikan konseling, dari kegiatan tersebut kemampuan komunikasi terlatih. Mahasiswa juga dituntut untuk bisa mengatur kegiatannya masing-masing kelompok maupun individu, sehingga kemampuan kepemimpinan juga terlatih, dengan demikian program CBME ini dengan sendirinya akan meningkatkan kemampuan soft skills mahasiswa khususnya kemampuan komunikasi dan kepemimpinan.

\section{Metode}

Rancangan penelitian yang digunakan adalah kuantitatif dengan dengan pre eksperimen one group pre-post test design..$^{6}$ Subjek dalam penelitian ini adalah mahasiswa kebidanan semester VI di Akademi Kebidanan YLPP Purwokerto. Sampel penelitian adalah total sampling sebanyak 79 mahasiswa. Instrumen penelitian penelitian menggunakan kuesioner. Pengumpulan data dilaksanakan di 4 desa binaan di kabupaten Banyumas. Data yang sudah dikumpulkan kemudian dianalisis, untuk metode kuantitatif menggunakan analisis deskriptif dan dilakukan uji t-test paired untuk menganalisis hubungan antar variabel.

\section{Hasil}

Berdasarkan data yang terkumpul dari 79 responden didapatkan hasil kemampuan kepemimpinan sebelum melaksanakan CBME pada mahasiswa Akademi Kebidanan YLPP sebagian besar mempunyai kemampuan kepemimpinan dalam kategori kurang mampu yaitu sebanyak 45 mahasiswa atau sebesar $57 \%$. Sedangkan kemampuan kepemimpinan sesudah melaksanakan CBME pada mahasiswa kebidanan Akademi YLPP sebagian besar mempunyai kemampuan kepemimpinan dalam kategori kurang mampu yaitu sebanyak 53 mahasiswa atau sebesar $67,1 \%$. Terjadi peningkatan sebesar $48,1 \%$ hal ini dikarenakan mahasiswa dapat melatih kepemimpinan mereka setiap waktu dalam kegiatan CBME, mulai dari kegiatan bangun tidur sampai menjelang akhir kegiatan mahasiswa dituntut untuk bisa memimpin diri sendiri dan kelompoknya.

Hasil analisis data kemampuan kepemimpinan dengan membandingkan sebelum melaksanakan CBME dengan sesudah melaksanakan CBME dengan $p$ value sebesar 0,000 , ada perbedaan kemampuan kepemimpinan mahasiswa sebelum dan sesudah melaksanakan CBME.
Tabel 1. Hasil Uji Perbedaan Kemampuan Kepemimpinan Mahasiswa Sebelum dan Sesudah Melaksanakan $C B M E$

\begin{tabular}{lccccc}
\hline \multirow{2}{*}{$\begin{array}{l}\text { Kemampuan } \\
\text { Kepemimpinan }\end{array}$} & $\begin{array}{c}\text { Sebelum Praktik } \\
\text { CBME }\end{array}$ & \multicolumn{2}{c}{$\begin{array}{c}\text { Sesudah Praktik } \\
\text { CBME }\end{array}$} & $\begin{array}{c}P \\
\text { value }\end{array}$ \\
\cline { 2 - 5 } & $\mathrm{n}$ & $(\%)$ & $\mathrm{n}$ & $(\%)$ & \\
\cline { 1 - 5 } Mampu & 4 & 5,1 & 15 & 19 & \\
Kurang Mampu & 45 & 57 & 53 & 67,1 & \multirow{2}{*}{0,000} \\
Tidak Mampu & 30 & 38 & 11 & 13,9 & \\
\hline Jumlah & 79 & 100 & 79 & 100 & \\
\hline
\end{tabular}

Kemampuan komunikasi sebelum melaksanakan CBME pada mahasiswa akademi kebidanan YLPP sebagian besar mempunyai kemampuan komunikasi dalam kategori kurang mampu yaitu sebanyak 54 mahasiswa atau sebesar $68,4 \%$. Kemampuan komunikasi sesudah melaksanakan CBME pada mahasiswa Akademi Kebidanan YLPP sebagian besar mempunyai kemampuan komunikasi dalam kategori kurang mampu yaitu sebanyak 56 mahasiswa atau sebesar $70,9 \%$, dan hanya terjadi peningkatan sebesar 7,5\% hal ini dikarenakan banyak faktor. Hasil analisis data terdapat perbedaan kemampuan komunikasi mahasiswa sebelum dan sesudah melaksanakan CBME.

Tabel 2. Hasil Uji Perbedaan Kemampuan Komunikasi Mahasiswa Sebelum dan Sesudah Melaksanakan $C B M E$

\begin{tabular}{|c|c|c|c|c|c|}
\hline \multirow{2}{*}{$\begin{array}{l}\text { Kemampuan } \\
\text { Komunikasi }\end{array}$} & \multicolumn{2}{|c|}{$\begin{array}{c}\text { Sebelum } \\
\text { Praktik } \\
\text { CBME }\end{array}$} & \multicolumn{2}{|c|}{$\begin{array}{c}\text { Sesudah Praktik } \\
\text { CBME }\end{array}$} & \multirow[t]{2}{*}{$P$ value } \\
\hline & $\mathrm{n}$ & $(\%)$ & $\mathrm{n}$ & $(\%)$ & \\
\hline Mampu & 10 & 12,7 & 11 & 13,9 & \multirow{4}{*}{0,000} \\
\hline Kurang Mampu & 54 & 68,4 & 56 & 70,9 & \\
\hline Tidak Mampu & 15 & 19 & 12 & 15,2 & \\
\hline Jumlah & 79 & 100 & 79 & 100 & \\
\hline
\end{tabular}

\section{Pembahasan}

Hasil analisis data yang telah dilakukan diketahui bahwa terdapat perbedaan kemampuan kepemimpinan sebelum dan sesudah melaksanakan CBME pada mahasiswa kebidanan Akbid YLPP dengan $p$ value 0,000. Hal ini dikarenakan, diterjunkan ke komunitas, mahasiswa menjadi bagian dari komunitas sosial dan medis di mana mereka belajar. Program CBME ini telah terbukti menjadi lingkungan belajar yang kuat, di mana mahasiswa mengembangkan keterampilan kepemimpinan yang kuat dan penalaran klinis sangat baik.

Hasil penelitian ini sejalan dengan penelitian Lee KH yang menyatakan bahwa kepemimpinan 
mahasiswa akan meningkat dengan mahasiswa belajar bersama dengan masyarakat. ${ }^{7}$ Pembelajaran berbasis masyarakat merupakan metode pembelajaran yang cocok untuk mahasiswa belajar mengenai isu-isu psikososial serta melatih kemampuan komunikasi, kepemimpinan dan kerjasama tim. Mahasiswa lebih tertarik belajar dikomunitas karena mahasiswa dapat secara langsung memberikan umpan balik kepada permasalahan yang sedang dihadapi oleh individu/ masyarakat. Melalui pendidikan berbasis masyarakat kemampuan soft skills mahasiswa akan meningkat terutama kemampuan komunikasi dan kepemimpinan., ${ }^{8,9}$

Pelayanan kebidanan merupakan pelayanan yang ditujukan kepada perempuan sejak masa sebelum konsepsi, masa kehamilan, persalinan, nifas, bayi baru lahir dan balita sepanjang siklus kehidupannya. Dengan pelayanan kebidanan yang berkualitas akan memberikan kepuasan kepada pelanggan maupun stakeholder. Agar pelayanan yang berkualitas tercapai diperlukan seorang pemimpin yang dapat meningkatkan terus mutu pelayanan kebidanan yang diberikan oleh organisasinya. Bidan dituntut harus mampu menerapkan aspek kepemimpinan dalam organisasi dan manajemen pelayanan kebidanan (KIA/KB), kesehatan reproduksi dan kesehatan masyarakat di komunitas dalam praktek kebidanan yang tertuang dalam Permenkes no. 149 pasal 8.

Beberapa kegiatan CBME pada mahasiswa kebidanan Akbid YLPP yang telah dilaksanakan untuk melatih kepemimpinan diantaranya menggerakan dan meningkatkan peran serta masyarakat, menyusun strategi pelayanan yang berkaitan dengan kebidanan komunitas secara berkesinambungan untuk pemecahan masalah, merumuskan masalah-masalah kebidanan komunitas dan mengidentifikasi masalahmasalah kebidanan komunitas. Kegiatan tersebut menjadi bentuk pelatihan yang dapat melatih mahasiswa dalam bidang kepemimpinan.

Pembelajaran di masyarakat pada hakekatnya mendekatkan dan memadukan peserta didik dengan lingkungannya, agar mahasiswa memiliki rasa cinta, peduli dan tanggung jawab terhadap lingkungannya. Pembelajaran dimasyarakat membekali mahasiswa dengan berbagai keterampilan untuk bisa mempertahankan lingkungannya serta mengembangkan diri secara optimal. ${ }^{10-12}$
Kerangka social cognitive theory (SCT) Bandura menyatakan bahwa faktor person/ kognitif, perilaku serta faktor lingkungan memainkan peran penting dalam pembelajaran. Faktor kognitif berupa ekspektasi/ penerimaan mahasiswa untuk meraih keberhasilan, faktor lingkungan mencakup pengamatan mahasiswa terhadap perilaku orang lain sebagai model. Menurut Bandura ketika mahasiswa belajar mereka dapat merepresentasikan atau mentrasformasi pengalaman mereka secara kognitif. Menggunakan kerangka SCT ini pembimbing/ masyarakat dalam lingkungan sebagai role model dapat berfungsi secara dinamis mampu mengubah lingkungan dengan mahasiswa melakukan pengamatan., ${ }^{9,13}$

Konsep utama dari teori belajar sosial adalah pemodelan (modelling) melalui proses pengamatan terhadap perilaku orang lain terutama pembimbing, pemimpin atau orang yang dianggap mempunyai nilai lebih dari orang lain atau dirinya. Didalam kegiatan CBME ini mahasiswa dihadapkan dengan berbagai karakter orang untuk dijadikan model oleh mahasiswa. Model tersebut antara lain bidan, pembimbing akademik (dosen), masyarakat (tokoh agama, tokoh masyarakat, dan lain-lain), serta teman sesama mahasiswa. Belajar pemodelan melalui pengamatan yang dilakukan oleh mahasiswa terhadap model seperti terhadap pembimbing baik dosen ataupun bidan serta tokoh masyarakat dalam kegiatan meningkatkan peran serta masyarakat untuk hidup sehat. Mahasiswa mengamati dan meniru apa yang dilakukan model saat memimpin kelompok masyarakat agar berperilaku hidup sehat. Mahasiswa menghubungkan pengalaman terdahulu saat dikelas dengan pengalaman saat ini dikomunitas untuk mahasiswa ulang kembali dikegiatan selanjutnya.

Setelah memperhatikan dan mengamati suatu model, maka pada saat lain mahasiswa memperlihatkan tingkah laku yang sama dengan model tersebut. Mahasiswa melakukan proses retensi atau mengingat dengan menyimpan memori mengenai model yang dia lihat dalam bentuk simbol-simbol. Bentuk simbol-simbol yang diingat ini tidak hanya diperoleh berdasarkan pengamatan visual, melainkan juga melalui verbalisasi. Ada simbol-simbol verbal yang nantinya bisa dtampilkan dalam tingkah laku yang berwujud. Mahasiswa menyimpan 
pengalaman belajar tersebut dalam ingatan untuk digunakan pada waktu yang akan datang.

Proses dilanjutkan dengan mahasiswa melihat kembali proses yang telah dilakukan, mahasiswa mengurutkan kembali komponen tingkah laku sudah dikuasai atau belum. Mahasiswa memberikan umpan balik terhadap komponen yang sudah benar atau hal-hal yang masih salah dalam penampilannya. Mahasiswa mulai melakukan kegiatan asuhan secara mandiri dengan meniru model, hal ini akan memberikan penguatan bagi mahasiswa yang telah menunjukkan perbuatan positif. Modeling lebih dari sekedar peniruan atau mengulangi perilaku model tetapi modeling melibatkan penambahan dan atau pengurangan tingkah laku yang teramati, menggeneralisir berbagai pengamatan sekaligus melibatkan proses kognitif.

Salah satu kegiatan mahasiswa dalam CBME tersebut sesuai dengan pola perilaku yang diklasifikasikan oleh Bandura pada fase belajar pemodelan yaitu fase atensi, fase retensional, fase reproduksi, dan fase motivasional. ${ }^{13-15}$ Namun dari penelitian, didapatkan hasil kemampuan kepemimpinan mahasiswa sebelum CBME dalam kategori mampu sebanyak 4 mahasiswa atau sebesar 5,1\% dan kemampuan setelah melaksanakan CBME sebanyak 15 mahasiswa atau sebesar $19 \%$ dikarenakan tidak semua mahasiswa melewati setiap fase belajar pemodelan tersebut dikarenakan untuk pemodelan tersebut dibutuhkan pengulangan dalam mendalami sesuatu yang ditiru, sedangkan dalam kegiatan CBME ini sendiri idealnya setiap mahasiswa mendapatkan kesempatan yang sama untuk belajar tetapi masih ada mahasiswa yang pasif dalam kegiatan CBME.

Keinginan memperhatikan dipengaruhi oleh kebutuhan-kebutuhan dan minat-minat pribadi. Semakin ada hubungannya dengan kebutuhan dan minatnya, semakin mudah tertarik perhatiannya; sebaliknya tidak adanya kebutuhan dan minat, menyebabkan seseorang tidak tertarik perhatiannya. Motivasi banyak ditentukan oleh kesesuaian antara karakteristik pribadi pengamat dengan karakteristik modelnya. Karakteristik model seperti kompetensi, prestise atau kekuasaan, perilaku sesuai gender, serta perilaku yang relevan dengan situasi mahasiswa saat pembelajaran berlangsung penting dalam menentukan tingkat peniruan.

Hasil analisis data yang telah dilakukan diketahui bahwa terdapat perbedaan kemampuan komunikasi sebelum dan sesudah melaksanakan CBME pada mahasiswa kebidanan Akbid YLPP dengan nilai signifikansi atau $p$ value sebesar 0,000 yang lebih kecil dari $0,05(0,000<0,05)$. Yang berarti terdapat perbedaan nilai kemampuan komunikasi mahasiswa sebelum CBME dan setelah CBME.

Hasil penelitian ini sejalan dengan penelitian Kelly ${ }^{16}$ yang menyatakan bahwa Community Based Medical Education memungkinkan mahasiswa menjadi bagian dari komunitas sosial dan medis di mana pembelajaran terjadi.Program CBME ini telah terbukti menjadi lingkungan belajar yang kuat, di mana keterampilan komunikasi mahasiswa dapat berkembang dengan dan maksimal.

Pendidikan berbasis masyarakat adalah konsep yang sangat luas, memberikan kesempatan yang luas kepada mahasiswa untuk berinteraksi dengan orang-orang dari berbagai latar belakang sosial, budaya dan etnis, sehingga membutuhkan kemampuan pengetahuan, keterampilan klinis dan sikap yang baik dari mahasiswa. ${ }^{14}$ Pendidikan berbasis masyarakat memungkinkan mahasiswa melakukan kunjungan rumah, sebagai contoh untuk perawatan bayi baru lahir. Kegiatan ini memberikan kesempatan kepada mahasiswa untuk terlibat langsung dalam permasalahan kesehatan di masyarakat sehingga kompetensi mahasiswa akan tumbuh dan berkembang untuk merencanakan dan memberikan perawatan kepada kasus yang sedang dihadapi. Melalui pendidikan berbasis masyarakat, masalah kesehatan individu/ masyarakat yang kompleks yang tidak dapat ditangani di rumah sakit tersier dapat terselesaikan.

Pendidikan kesehatan berbasis masyarakat mempersiapkan mahasiswa kesehatan untuk bekerja di dalam dan dengan masyarakat. Mengintegrasikan kemampuan komunikasi dengan kunjungan ke pusat-pusat kesehatan membantu dalam meningkatkan sikap terhadap kemampuan berkomunikasi. Pendidikan kesehatan berbasis masyarakat dapat membantu mahasiswa untuk meningkatkan kemampuan dalam berkomunikasi, dan manajemen kepemimpinan dan kewirausahaan. ${ }^{18-20}$

Pelaksanaan CBME menuntut mahasiswa untuk dapat berkomunikasi kepada masyarakat dengan baik. Kegiatan yang dilakukan mahasiswa Akademi Kebidanan YLPP dalam belajar berkomunikasi diantaranya memberikan 
penyuluhan kesehatan maupun pendidikan kesehatan kepada ibu, remaja dan lansia di lokasi kegiatan. Lokasi kegiatan CBME ini terbagi berdasarkan 4 kelompok desa di daerah binaan wilayah kerja Puskesmas dan Kecamatan Karang Lewas Kabupaten Banyumas. Desa tersebut yaitu desa Pangebatan, Karang Lewas Kidul, Babakan, dan Taman Sari.

Permasalahan masyarakat yang menjadi prioritas dalam kegiatan ini diantaranya di lokasi desa Pangebatan yaitu anemia, KEK, Risti, ASI Eksklusif, ISPA, Posyandu Lansia. Sedangkan program kegiatan bagi masyarakat diantaranya pemeriksaan ANC, bank sampah, pengaktifan posyandu lansia, kegiatan jalan sehat, kegiatan donor darah, kegiatan PHBS, kegiatan penyuluhan kanker payudara dan kanker serviks, serta kegiatan penyuluhan HIV dan Kespro.

Pendidikan berbasis masyarakat ini memiliki kunci penting, yaitu masyarakat dilibatkan sebagai subjek atau pelaku bukan objek yang hanya menerima sistem pendidikan saja. Masyarakat pun diajak untuk bertanggung jawab dari awal perencanaan hingga pada pelaksanaan pendidikan di wilayahnya masing-masing. Hal menggambarkan bahwa masyarakat lebih tahu apa yang mereka inginkan dan potensi apa saja yang dapat dikembangkan dengan diadakannya fasilitas pendidikan yang ada di daerahnya. Masyarakat juga sangat memerlukan pendidikan untuk bisa keluar dari permasalahan setempat.

Namun dari penelitian didapatkan hasil kemampuan komunikasi mahasiswa sebelum melaksanakan CBME dalam kategori mampu sebanyak 10 mahasiswa atau sebesar $12,7 \%$ dan kemampuan setelah melaksanakan CBME sebanyak 11 mahasiswa atau sebesar 13,9\% dan hanya terjadi peningkatan sebesar 7,5\% dikarenakan adanya kecemasan, diantaranya takut menerima tanggapan atau penilaian negatif dari orang yang menerima pesan. Kegiatan CBME ini sendiri mampu menumbuhkan sikap percaya diri, karena mahasiswa mendapatkan kesempatan untuk belajar tetapi masih ada mahasiswa yang pasif dalam kegiatan CBME.

\section{Simpulan}

Community Based Medical Education (CBME) merupakan salah satu metode pembelajaran yang efektif untuk meningkatkan kemampuan kepemimpinan dan komunikasi mahasiswa kebidanan.

\section{Daftar Pustaka}

1. Sarfraz M, Hamid S. (2014). Challenges in delivery of skilled maternal care experiences of community midwives in Pakistan. BMC Pregnancy and Childbirth.

2. Herizon, Wirda F. (2012). Pengembangan soft skills melalui pendekatan student center learning di perguruan tinggi. Polibisnis. 2012;4(2).

3. Koesno H. Bidan yang berkarakter. Bidan (Media Komunikasi Bidan \& Keluarga Indonesia). 2009.

4. Sailah I. (2008). Pengembangan soft skills di Perguruan Tinggi2008. Available from: http://isailah.50webs.com/Buku Pengembangan Soft Skills 2008. pdf

5. Urif FA. Praktik kerja lapangan. Bidan (Media Komunikasi Bidan \& Keluarga Indonesia). 2011.

6. Sugiyono. Metode penelitian kuantitatif, kualitatif dan kombinasi (Mixed method). 2 ed. Bandung: Alfabeta.

7. Lee KH. Nurse midwifery education through graduate programs to provide a sufficient number of high quality nurse midwives. Journal of Education Evaluation for Health Professions. 2006;3(5).

8. Haselberger D, Oberhuemer P, Perez E, Cinque M, Capasso F. Mediating soft skills at higher education institutions: Guidelines for thr design of learning situations supporting soft skills achievement.

9. Mann KV, Holmes DB, Hayes VM, Burge FI, Viscount PW. Community family medicine teachers' perceptions of their teaching role. Medical Education. 2001;35:278-85.

10. Kelly L, Walters L, Rosenthal D. Community based medical education: Is success a result of meaningful personal learning experiences? Education for Health. 2014;27(1).

11. Kesuma D, Triatna C, Permana J. Pendidikan karakter: kajian teori dan praktik di sekolah. Bandung: PT Remaja Rosdakarya; 2012.

12. Padjadjaran FKU. Laporan studi diagnostik kemampuan bidan lulusan program studi D3 kebidanan dalam memberikan pelayanan bagi masyarakat di Jawa Barat. Bandung: Universitas Padjadjaran; 2004.

13. Graeff JA, Elder JP, Booth EM. Communication for health and behavior. Yogyakarta: Gadjah mada university press; 1996.

14. Hergenhahn BR, Olson OMH. Theories of learning (Teori Belajar). 7, editor. Jakarta: Kencana Prenada media Group; 2008.

15. Santrock JW. Psikologi pendidikan. 2, editor. Jakarta: Kencana; 2008.

16. Kelly L, Walters L, Rosenthal D. Community based medical education: Is success a result of meaningful personal learning experiences? Education for Health. 2014;27(1).

17. Mennin S, Mennin RP. Community based medical education. The clinical teacher. 2006;3:90-6

18. HPEQ. Draft Standar Kompetensi Bidan Indonesia 26 november 2013;2011.

19. Mangkunegara AP. Perencanaan dan pengembangan sumber daya manusia. Bandung: PT Refika aditama; 2009.

20. Astuti WD, Budijanto D. Kemampuan soft skill sumber daya manusia kesehatan di Kabupaten Bojonegoro dan Magetan provinsi Jawa Timur. Jurnal Manajemen Pelayanan Kesehatan. 2009;12(4):193-8. 
Evi Sri Suryani : Pengaruh implementasi praktik CBME terhadap peningkatan soft skills kepemimpinan dan komunikasi

52|IJEMC, Volume 2 No. 3, September 2015 